\title{
A Reappraisal of Trade Deficit and Income Inequality in the United States:
}

\author{
$1985-2007$ \\ Yan Li (Corresponding author) \\ Department of Economics, University of Wisconsin - Eau Claire \\ 105 Garfield Ave. P.O.Box 4004; Eau Claire, WI; 54702-4004, U.S. A \\ Tel: 1-715- 836-3507Ｅ-mail: liyan@uwec.edu \\ Christopher Thompson \\ Department of Economics, University of Wisconsin - Eau Claire \\ 105 Garfield Ave. P.O.Box 4004; Eau Claire, WI; 54702-4004, U.S. A \\ Tel: 1-715-864-2628Ｅ-mail: thompscs@uwec.edu
}

JEL Codes: $\mathrm{O} 15$

\begin{abstract}
Acknowledgements
The authors acknowledge the financial support provided by the Office of Research and Sponsored Programs (ORSP) and the Department of Economics at the University of Wisconsin - Eau Claire. We are grateful to Xiangming Fang for technical assistance, to Wayne Carroll for generous support, and finally to Dennis Petruska for all the helpful comments. Thanks also go to two anonymous referees and the conference participants at the Missouri Valley Economics Association Annual Meeting (2008) and the Wisconsin Economics Association Annual Meeting (2008).
\end{abstract}

\begin{abstract}
The recent resurgence of income inequality in the United States has spawned a wide-ranging discussion to its causes, which has often focused on America's historically high trade deficit in the past two decades. Our paper revisits this issue by investigating the latest trends in the U.S. income disparity from 1985 to 2007 , and systematically examining the factors that might have influenced the income inequality. To better understand income disparity, three different measures are employed: Gini, Theil and Atkinson indices. Results show that, only in the cases of Gini and Theil, international trade explains a part of income inequality, but it surely cannot be the whole story. Other factors, such as the net migration rate, the changing role of women, and the sectoral distribution of employment also play important roles in accounting for America's income inequality.
\end{abstract}

Keywords: Income Inequality, Trade Deficit, Gini, Theil, Atkinson

\section{Introduction}

The recent resurgence of income inequality is one of the most difficult economic problems confronting the world today, which poses great challenges to policymakers in both advanced industrial societies and emerging market economies.

Kuznets (1953 and 1955) conjectures that income inequality will first rise, peak, level off and then decline as an economy reaches a certain level of prosperity. In the case of the U.S., for instance, historical data before 1920s had verified the success of Kuznets hypothesis. However, the more recent empirical facts suggest a radical reversal of Kuznets's findings. Harrison and Bluestone (1988) identified a "great U-turn" in the development pattern of income inequality, which presents the phenomenon of widening income disparity in the U.S. after the 1960s. At the same time, such an upswing in inequality has also been experienced by other developed countries such as the United Kingdom. As Bernanke (2008) points out, even though average economic well-being has increased considerably over time, the degree of inequality in economic outcomes over the past three decades has increased as well. Economists are eager to grapple with the reasons for this trend, which has spawned a wide-ranging debate with no consensus that has been achieved by far. Diverse factors that might influence income inequality have been proposed, and among them, globalization is most frequently under the spot light.

Our paper aims to fill the gap in the literature by documenting the most recent trends in the U.S. income disparity from 1985 through 2007, and then studying the distributional impact of globalization, in particular, the trade deficit, on the inequality. 
Two features are noteworthy here. First of all, in previous literature, globalization is usually measured in terms of foreign direct investment (FDI), the north-south trade and migration. In the current framework, we introduce a new element in addition to those three distinct aspects and evaluate the degree of openness in terms of the trade balance with the rest of the world. Statistics show that in the past two decades, the U.S. trade deficit has soared to unprecedented heights, surpassing the levels reached in the 1980s. This record deficit is fueling public concerns that it could badly hurt the U.S. economy by destroying domestic jobs, lowering wages, raising corporate profits, burdening future generations, and in turn leading to a rising income inequality. Some trade protectionists therefore, advocate that international trade should be boycotted in order to eliminate the negative impact of globalization on income distribution. Is their argument true? Is the U.S., as they claimed, trading away its future? Our paper tries to answer this question by applying a generalized linear regression model to assess the ways in which the trade deficit relates to the income inequality.

Secondly, to better understand the income disparity, three different measures are employed, among which the Gini coefficient is so far the most popular and widely used indicator. However, Gini coefficient is not always an adequate measurement of inequality, since it is only able to provide a general image of the level of aggregate income disparity. Our paper contributes to the literature by incorporating another two metrics into our model: Theil index and Atkinson index. Therefore, a more accurate description of the impact of globalization on the actual income distribution is presented.

Our results show that, only in the cases of Gini and Theil indices, international trade explains a part of income inequality. It is found that the imports from southern countries and trade deficit actually decrease Gini index by pushing down the aggregate price level and therefore improving the overall economic conditions. In addition, trade deficit tends to shrink the disparity at the higher end of the income spectrum as well, measured by Theil index, but its role appears to be secondary. In the case of Atkinson coefficient, the impact of trade on income inequality is not significant at all. Other factors, such as the changing role of women, the net migration rate and the sectoral distribution of labor force are also found to be very important in accounting for America's rising income disparity in the last two decades.

The remainder of this paper is organized as follows. In Section 2, we present a brief review of the literature on globalization and income inequality. In Section 3, the empirical evidence of U.S. income inequality from 1985 to 2007 is introduced. In Section 4, we set up a generalized regression model with a set of explanatory factors to understand such a rising inequality. In Section 5, the regression results are presented and policy measures will be briefly discussed. Section 6 is a conclusion.

\section{Literature Review}

By far, a number of empirical studies have contributed to the literature by investigating the channel through which globalization affects income inequality. The results, however, are mixed.

For example, Mahler (2001) finds little evidence of a systematic relationship between globalization and income distribution. Instead, politics continues to dominate in determining distributive outcomes in the developed world. On the other hand, Miller (2001) argues that a significant increase in income disparity results from globalization. Such economic integration has changed the structure of production in U.S. by outsourcing unskilled-intensive jobs to low-income countries, and therefore depressed the relative wages of unskilled workers in the U.S. since the late 1970s. Almost at the same time, Dollar and Kraay (2002) obtain some other interesting results. They use an unbalanced data of 92 countries spanning four decades $(1960$ - 1999), and show that the openness to international trade has insignificant effect on the income share of the bottom quintile. Then, Scott (2001) maintains that international trade itself does not suffice to assume convergence of income between countries. He points out that immigration barriers set up by the highly developed countries prevent wage equalization and therefore create wider income gaps.

In sum, there is a large body of literature examining the impact of globalization, particularly, international trade, on income distribution. Alderson and Nielsen (2002) is one of the most influential pieces of work. Their study represents one of the first systematic, cross-national examinations of the role of globalization in the inequality "U-turn". The results indicate that the percentage of the labor force in agriculture dominates globalization in explaining the increasing trend in inequality within and across countries. However, their work is subject to substantial data limitations. Only 57 observations from the Luxembourg Income Study (LIS) are available for 16 Organization of Economic Co-operation and Development (OECD) countries and therefore, methods of estimation have to be employed to provide more comparable information. The paucity of data, with no doubt, has hampered their cross-national and longitudinal study. Moreover, all observations focus on the period from the late 1960s to the early 1990s.

Our paper follows the footsteps of Alderson and Nielsen and tries to explain the most recent patterns in the U.S. income inequality. A panel data set is carefully assembled, containing 575 observations for 25 variables over 23 years, i.e. 1985-2007 (see Table 1 for details). 


\section{An Overview of the U.S. Income Inequality}

A natural place to begin is by studying the empirical evidence. The following section first presents the overall trend in the U.S. income inequality. Then, the impulse function from a "structural vector autoregression" (VAR) estimation is employed to demonstrate the impact of international trade on income disparity.

\subsection{Income inequality and economic development}

[Figure 1, 2 and 3 here]

Gini coefficient by far has been used the most extensively in the literature. It is derived from the Lorenz curve, which shows the percentage of total income earned by cumulative percentage of the population. This coefficient is a number between 0 and 1, which describes the degree of evenness of income distribution in a country. In general, a lower Gini coefficient indicates a more equitable distribution of wealth, while a higher Gini value implies a more economically polarized society.

Gini coefficient is easy to generate, but is incapable of differentiating different kinds of inequalities. By assigning varying weights to different parts of the income spectrum and incorporating implicit social judgments, Atkinson (1983) introduced a new method - the Atkinson index. This measure is more concerned about inequalities at the bottom of the income distribution. Based on Atkinson, the Theil index was then developed. As an alternative inequality indicator, it pays more attention to inequalities at the top of the income distribution. For convenience, we multiply all three types of inequality coefficients by 100 and express them as an index between 0 and 100 .

Since a large body of literature has examined the U.S. income disparity before 1990s, our paper therefore, will focus on its latest trend over 1985 through 2007. Figures 1 and 2 present the evolution of U.S. income inequality measured by Gini, Theil and Atkinson coefficient respectively. Ignoring the short-term variation, we observe a clear upswing in the overall income inequality since the mid 1980s. In particular, the Gini indices over the past two decades were all above 40 , a level typically interpreted by economists as an "unfair" income distribution.

Figure 3 plots the logged real GDP (base 10) per capita against the income inequality, where the former is usually a measure of the economic development. As mentioned earlier, the Kuznets hypothesis suggests that a negative relationship between inequality and development should be found for advanced industrial societies. However, the recent stylized facts in the U.S. evidently show the opposite, which is demonstrated by the ascending slope of inequality and economic development in Figure 1, 2 and 3.

\subsection{The impact of trade balance on income inequality}

[Figure 4 here]

To take a closer look at the relationship between globalization and income inequality, we estimate a structural four-variable VAR, including trade balance, Gini, Theil and Atkinson indices (see Note 1). Dynamic response functions are calculated and reported in Figure 4, which provides a convenient framework to investigate the impact of globalization on income disparity.

In this scenario, globalization is represented by trade balance. At the beginning, a temporary positive shock is introduced in trade balance, and then the responses in these three inequality indices are observed. It is clear that under a positive shock in trade balance (or trade surplus), all three indices rise on impact. A higher inequality index indicates a more polarized society, and vice versa. Therefore, Figure 4 shows that an improving condition in trade balance does not necessarily result in better social welfare as some economists expect. The opposite might occur instead as suggested by these VAR findings. In recent decades, a great deal of literature has concerned about the negative effect of the worsening U.S. trade balance on its income inequality. However, strong empirical evidence is absent to support such arguments. Starting in the next section, we will explore in details the ways that important economic indicators relate to the income inequality in the U.S., and then try to estimate the importance of each of them.

\section{Methodology}

What drives up the U.S. income inequality? The previous studies suggest that there is no single "smoking gun". After a thorough review of the stylized facts, we will proceed with an assessment of some leading factors that have been advanced to explain the income disparity.

\subsection{Model}

In this section, the model of income inequality devised by Alderson and Nielsen (2002) is borrowed and then expanded to test hypotheses regarding the distributional impact of globalization, in particular, the trade deficit. The core model can be specified as follows:

$$
\text { ineq }=f\left(s d u_{i t}, l_{t}, m_{t}, \text { dem }_{t}, e d u_{t}, \text { union }_{t}, \text { glob }_{t}\right)
$$


where ineq is a particular inequality metric, such as Gini, Atkinson or Theil; sdu is the sector dualism, where $i=\mathrm{a}$, manu, and s, denoting the agricultural, manufacturing and service sectors, respectively. Additionally, $l$ is the aggregate labor market conditions, $m$ is the monetary stability, dem is the demographic transition, $e d u$ is the overall education, union is the density of unionization, and finally glob represents the globalization. In the following section, we will explain how the above factors are measured.

\subsection{Data}

\subsubsection{Sector dualism}

The generalized sector dualism, as defined by Alderson and Nielsen (2002), measures the contributions to the overall inequality of differences in average income between sectors and the relative size of the sectors. The agricultural dualism, for instance, is written as

$$
s d u_{a}=\left|l_{a}-g d p_{a}\right|
$$

where $s d u_{a}$ is the agricultural dualism, $l_{a}$ is the percentage of labor force in agriculture and $g d p_{a}$ is agriculture's share of GDP. The absolute value is taken to guarantee a positive value in the hypothetical case where the agricultural sector is more productive than the nonagricultural ones. The dualism for the manufacturing and service industry, can be defined in a likewise manner as follows

$$
\begin{gathered}
s d u_{m}=\left|l_{\text {mапи }}-g d p_{\text {mапи }}\right| \\
s d u_{s}=\left|l_{s}-g d p_{s}\right|
\end{gathered}
$$

\subsubsection{The aggregate labor market conditions}

Three important aspects of the aggregate labor market conditions will be studied. Firstly, the distribution of the labor force across sectors. As proposed by Kuznets (1955), the agricultural sector, for instance, is typically associated with the lowest income inequality. Thus, the larger the agricultural sector, the lower the overall inequality. The indicator $l_{i t}$ is used to describe the sectoral size of labor force and the dynamic shifts taking place across sectors, where $i=\mathrm{a}$, manu, and s. Secondly, we examine the changing role of women. Two kinds of arguments are taken into consideration. One studies the distributional implications of the increasing female labor force participation, and the other focuses on the rising proportion of households headed by women. Due to women's lower average earnings, either of these two factors is expected to be associated with a greater income disparity. Thirdly, the impact of the unemployment on income disparity is considered. It is well known that the turnovers in the labor market are likely to change the economic well-being of the workforce and therefore, lead to the relocation of household income.

\subsubsection{The monetary stability}

The recent literature has found that monetary policy and income inequality are possibly related (Fowler and Wilgus (2008)). The empirical evidence shows that, unexpected inflation acts to redistribute income by taxing the poor more heavily, since they hold a larger fraction of their wealth in cash. On the other hand, Bernanke (2003) argues that under certain conditions, accommodative monetary policy is able to mitigate the inequality. In this model, the monetary stability is captured by the annual inflation rate and fluctuations in the federal funds rate.

\subsubsection{The Demographic transition}

The shifts in the age distribution of the labor force are studied by looking at two variables here. One is the natural rate of population increase, which focuses on the cohort of young (less skilled) workers and the other is the seniority ratio of the population, measured by the percentage of people who are over 65 years old. The life-time income profile for an average worker shows that the youth and seniority are usually at the bottom of the earnings scale. As a result, we expect that both variables will exert positive effects on income disparity.

\subsubsection{Education}

It is important to recognize that the wage gap between college graduates and those with a high school education or less has widened since the middle 1980s. Such a shift in the return to education implies that the educational attainment of the workforce surely affects income disparity. This dispersion of education is measured by the college graduates ratio. Greater access to high education and training is able to increase the share of population that can take advantage of the technological progress. The rising premium on higher skills in recent decades is associated with an increasing income inequality. For a given level of technology, another related factor is the diffusion of education, which reflects the average education level in a society and is measured by the overall secondary school enrollment ratio. A more diffused education is expected to reduce the income disparity by improving the general living standards of the labor force.

\subsubsection{Unionization}

In the past twenty years, the union power has been declining and the trend shows every indication of continuing in the near future. In this model, the union density is measured as the total union members as a percentage of total wage and 
salaried employees. Most researchers believe that the declining union power is due to the spread of skill-based technology jobs. During the period of deunionization, income inequality obviously climbed up. We will check the ways in which these two trends are related.

\subsubsection{Globalization}

To account for the rising income inequality in recent decades, the role of globalization cannot be ignored. In previous literature, the distributional impact of globalization on income is mixed. Typically, globalization is measured by three distinct dimensions: growing capital mobility (FDI/GDP), southern import penetration/GDP, and the net migration rate. To provide a well-round study of the distributional impact of globalization, another indicator is embedded into this framework: the trade balance/GDP. We will investigate their separate contributions to income inequality. To simplify our analysis of southern imports, two countries are specifically chosen, China and Mexico, the two developing countries among the U.S.'s top five trading partners. The trade deficit is the U.S.'s trade indebtedness with the rest of the world.

\section{Results and Policy Analysis}

Research on inequality has re-entered the mainstream development policy agenda by the World Bank since 2000. Why income inequality arises, persists and exacerbates are frequently debated issues among economists. Another central point of contention is how to appropriately measure income inequality itself. In fact, a variety of methods exist and yet a consensus has not emerged. To develop a more nuanced understanding of the income distribution, two additional measures (Theil and Atkinson indices) are considered in this paper besides Gini coefficient.

Now, a question naturally occurs. Will the impact of globalization on income inequality depend on the choice of inequality measures? Kawachi et. al (1996) answers "no". By comparing the behavior of six different measures of income inequality, their analysis indicates that the measures work very similarly and are highly correlated, with Pearson correlations ranging from 0.86 to 0.99 . In the next part, we will examine the robustness of the distributional hypothesis of globalization under three inequality measures.

\subsection{Regression results}

To avoid paradoxical regression results, it is necessary for us to first perform a simple diagnostic test of collinearity. Variables falling in the same category, such as labor market conditions, measure essentially the same thing, and therefore are usually highly correlated with each other. The variance inflation factor (VIF) for each variable is calculated. Values of VIF exceeding 10 are considered evidence of collinearity (see Note 2). Then we remove those variables with intolerable VIF values from our model to reduce the possibility of collinearity.

The regression results indicate that, not every factor proposed above is found to be statistically significant in affecting the U.S. income inequality. We drop one insignificant explanatory variable at a time from the regression until the remaining factors in the model are all shown to be significant. The main findings are presented in Tables 2-4, where STD is the standard deviation of the estimated coefficients, and the relative importance indicates the relative impact of each significant factor on inequality outcomes, which allows us to evaluate the substantive importance of each variable. Note that we are only interested in the "absolute values" of the relative importance (see Note 3 for more details).

[Table 2, 3 and 4 here]

It is shown that the choice of inequality indicator does indeed matter for the results generated by the analysis. We see several similarities and also very notable differences across three indices. In the following section, we will attempt to explore these results and explain how they have been affected as such.

In Figure 1, the inequality is severed in the mid-1990s, and a high-jump is clearly observed. A time dummy variable is thereby used to capture this effect. The dummy equals 1 , if the period is prior to 1992 . Otherwise, the dummy is 0 . The results indicate that a negative relationship exists between this dummy and Gini index. The same phenomenon arises across three indexes. Obviously, there should be some major events that have caused such an upswing in the inequality. We might be able to attribute this sudden jump in income inequality in the middle 1990s to three distinct factors: (1) the NAFTA (North American Free Trade Agreement) was enacted on January 1st of 1994; (2) the sudden increase in CEO incomes with the apparent rise in the stock markets was also concurrent with this time; (3) the adverse consequence of a wide-spread banking crisis in late 1980s and the early 1990s. The NAFTA greatly increased the trade volume and has been a contributor to the variations in trade balance, which in turn affects the income disparity. The increase in CEO incomes and the crashed financial system are likely to result in a greater income gap.

Next, the sector dualism, which explains the difference in average income between sectors, still remains a significant predictor of inequality. For instance, agricultural dualism negatively relates to Gini coefficient, which sheds light to Alderson and Nielsen (2002). Service dualism is found to be positively related to Atkinson index. In the past two decades, technological progress has been shifting employment from the agriculture to the manufacturing and service. Even though service industry is generally typified by a higher productivity and average wages, many people at the bottom of income distribution still have to work for low-pay service jobs, such as waiting tables in restaurants. Hence a 
higher income disparity at the bottom quintile (measured by Atkinson index) resulted from such an intra-industry labor movement.

By checking the role of women, we find that the percentage of females in the labor force and the percentage of female-headed households explain part of the story. Technological progress and the change of social value have allowed more females to get out of housework and bring additional earnings back home. This surely helps reduce the disparity among low-income households and lower the value of Atkinson index, as we see in Table 3. However, the fact that more women begin to participate in labor force or lead the household, does not necessarily imply that more equality will be created in the whole society. According to the survey by the National Bureau of Economic Research, women are earning significantly less than their male counterparts. The situation is even worse for female professionals, for instance, women who have MBA degrees and work in finance or business services. Such growing gender gaps generate a positive effect on both Gini and Theil index.

Seniority is also playing a part in income inequality measured by Gini index. Most seniors live off of a fixed income, such as social security or pension funds. Therefore, we expect that a bigger percentage of seniority will positively affect the income inequality, which is verified by the results in Table 2 . With a more aging population, the income inequality will surely rise.

We find a curious case when investigating the impact of education on inequality. The large increase in educational attainment earlier in the twentieth century produced greater economic equality and shared prosperity. However, we did not obtain enough evidence in our model to support such a point of view for the period of 1987 through 2007 . The two measures of education, college graduates ratio and secondary school enrollment ratio, are both found insignificant in accounting for the recent rise in economic inequality. In terms of the Atkinson index, we find a small negative but insignificant relationship, which exactly fits the traditional theory: more educated population would bid inequality down. Since the Atkinson index focuses more on the bottom of the income profile, it seems that education still remains the primary way for the poor to get out of poverty.

Then, let us examine the aggregate labor market conditions by checking the union density. A stronger union is associated with a rise in the income share of the poor and better welfare for workers, particularly for low-income workers. That is why the union density negatively relates to the Atkinson index. It is insignificant in another two cases.

Another interesting result is the impact of monetary stability on inequality. In Table 4, inflation produces a positive effect on Theil index, the measure of the inequality among the high-income people. As we know, the financial sector has claimed an ever-growing share of the nation's income over the past generation, making the people who run the industry wealthy. It makes sense that a higher inflation reduces the value of financial assets and shatters the confidence in financial market, which possible leads to a higher income gap between the rich and the hyper-rich.

Now, we turn to the standing-out result in this model, the impact of globalization on income inequality, which is illustrated by four distinct aspects: trade balance, imports from southern countries, net migration rate and FDI inflow to the U.S.

The role that international trade has played in explaining inequality patterns is demonstrated by the trade balance and southern imports. In the case of Gini coefficient, it is found that the U.S. trade deficit and imports from southern countries both have significantly reduced the income inequality. Statistics show that the imports from southern countries help narrow down the income gap by reducing the aggregate price level. It hence increases the effective income and improves the overall economic conditions in a country. In the case of Theil index, trade deficit relates to income inequality in a negative way. This is equivalently saying that a positive trade balance results in a wider income gap, which is associated with a higher Theil index. This actually matches the impulse response of Theil coefficient demonstrated in Figure 4.

Another important component of globalization that has contributed to a higher income disparity is the net migration rate. It exerts significant effects on each of the three indices. The recent migration has been mostly from the South and the Central America. Many immigrants from these regions have lower incomes and are more willing to work for less pay, which exacerbates the income inequality accordingly. In addition, the immigrant population is highly bifurcated. Many of them are very low-skilled as we just discussed. By contrast, many are highly skilled and / or even very rich, like immigrants from Europe and East Asia. Such two-polarized immigrants' skills tend to expand the inequality measured by all three indices.

FDI inflow is supposed to spread technological progress across countries, and therefore result in productivity advancement and a generally higher income. It is expected to lower inequality. However, in our study, it seems to be an insignificant variable.

\subsection{The relative importance of factors}

Finally, let us check the transformed regression coefficients in Tables 2-4 and compare the importance of explanatory variables based on the relative strength of their effects on inequality. Table 2 shows that the strongest influence on Gini 
index comes from the seniority ratio. Specifically, if the seniority ratio rises by 1 standard deviation, the Gini coefficient will accordingly increase by 0.5663 units of standard deviation. International trade takes the fifth position on the list. In Table 3, the most important factor that affects Atkinson index is the union density besides the dummy variable. International trade does not show significance in this scenario however, which lends support to Dollar and Kraay (2002). In Table 4, it is clear that international trade influences Theil index negatively. Its role is pretty small though.

To summarize, the inequality upswing may be due to a combination of factors. Globalization does not necessarily worsen the income distribution. Other factors, such as the changing role of women, seniority, union density and net migration rate play important roles in accounting for the rising income inequality in the U.S. as well.

\subsection{Policy analysis}

Understanding the possible causes of income inequality is the key to devising policy measures. To achieve a more egalitarian society, we should encourage the government to pursue social policies along the following dimensions.

Globalization is the long-term trend nowadays. The economic interdependence among countries will only become stronger in the future. Our empirical results are consistent with the classical theory of international trade. Overall, trade will increase prosperity in a country due to specialization and product differentiation in the globalized market. Trade is not the evil force that drives up the U.S. income disparity in recent decades. Therefore, trade protectionism is not the right solution that any government should adopt to fight poverty.

To increase the number of people who are able to win from globalization, the government should encourage a more flexible, mobile labor force. There is some evidence that trade will cheapen labor by exporting some low-skilled jobs overseas. If the less skilled labor cannot successfully shift to more productive tasks in service or manufacturing, they will lose because of such international relocation, which leads to a rising income disparity. Hence, the government should invest more heavily into education and further training. Increased and better access to higher education will definitely provide more opportunities to a greater share of population (including the immigrants) and help them engage in high-skill activities. That is greater access to education would make the endogenous sectoral and demographic transition much easier.

The government should also try to provide a more effective shield to the female labor force and strengthen their social competence. Additional assistance to female employees might be helpful to narrow down the gender gap in terms of income. For example, better child care will help prolong women's working hours and increase their average earnings. Income support may also be given to female headed households.

Last, but not the least, more priority should be given to the senior citizens. The government should provide a safety net with better health care and retirement benefits to the senior.

\section{Conclusion}

The last decade has witnessed dramatic developments in social economics with substantial contributions to both the theory and the empirical understanding of income inequality. However, a number of challenges remain. Why income inequality arises, persists and expands are frequently debated issues among economists, which have received extensive attention in recent years.

However, there has been no consensus in the literature on the causes of inequality upswing. The previous studies suggest there is no single "smoking gun". A growing literature has attempted to understand the expanding income inequality by focusing on skill biases due to technological progress. At the same time, some economists blame globalization, in particular the historically high trade deficit for America's rising income inequality.

This paper documents the resurgence of income inequality in the U.S. by collecting the latest data from 1985 to 2007. To provide a more complete picture of income distribution, three different inequality measures are particularly employed: Gini, Theil and Atkinson index. Then a generalized linear regression model is used to estimate the extent and channels through which all kinds of factors influence the income distribution.

Our results show that international trade does not play a starring role in explaining changes in recent inequality. In the cases of Gini and Theil index, international trade does affect income inequality, but it surely cannot be the whole story. Other factors, such as the changing role of women, union density, net migration rate, sectoral dualism and even inflation play quite important roles in accounting for America's rising income inequality. In the case of Atkinson coefficient, the effect of trade on income inequality is not significant at all. Therefore, international trade generates different distributional impact on different income groups.

Inequality matters in its own right and it is fundamental to combating poverty. Our study is a systematic and novel examination of the recent income inequality in the U.S., which provides a very nice framework for government policy evaluations. 


\section{References}

Alderson, A., \& Nielsen, F. (2002). Globalization and the Great U-Turn: Income Inequality Trends in 16 OECD Countires . American Journal of Sociology, 107:5, 1244-1299.

Atkinson, A. B. (1983). The Economics of Inequality. USA: Oxford University Press.

Atkinson, A. B. (2004). The Luxembourg Income Study (LIS): past, present and future. Socio-Economic Review, 2 , 165-190.

Bernanke, B.S. (2003). The Jobless Recovery. Remarks at the Global Economic and Investment Outlook Conference, Carnegie Mellon University.

Bernanke, B.S. (2008). Remarks on Class Day 2008. Harvard University.

Compton, C. (2004). All Men Created Unequal: Trends and Factors of Inequality in the United States. Issues in Political Economy, 13, 1-16.

De Maio, F. (2007). Income Inequality Measures. Journal of Epidemiology and Community Health, 61, 849-852.

Dollar, D., \& Kraay, A. (2002). Growth is good for the Poor. Journal of Economic Growth, 7, $195-225$.

Fowler, S. \& Wilgu, J. J. (2008). Income Inequality, Monetary Policy, and the Business Cycle. Working paper.

Gibson, J., Huang, J., and Rozelle, S. (2001). Why is Income Inequality So Low in China Compared to Other Countries? The Effect of Household Survey Methods . Economic Letters, 71, 329-333.

Harison, B. \& Bluestone, B. (1998). The Great U-Turn. New York: Basic Books.

Kawachi, I., Kennedy, B.P. \& Prothrow-Stith, D. (1996). Income Distribution and Mortality: Cross Sectional Ecological Study of the Robin Hood Index in the United States. British Medical Journal, 312, 1004-1007.

Kuznets, S. (1953). Shares of Upper Income Groups in Income and Savings. New York: National Bureau of Economic Research.

Kuznets, S. (1955). Economic Growth and Income Inequality. American Economic Review, 45, 1-28.

Koopmans, L. (1987). Introduction to Contemporary Statistical Methods. Boston, Mass: Duxbury Press.

Mahler, V.A. (2001). Economic Globalization, Domestic Politics and Income Inequality in the Developed Countries: a Cross-national Analysis. Luxembourg Income Study Working Paper, No. 273.

Miller, T.C. (2001). Impact of Globalization on U.S. Wage Inequality: Implications for Policy. North American Journal of Economics and Finance, 12(3), 219-42.

Nielsen, F. (1994). Income Inequality and Industrial Development: Dualism Revisited. American Sociological Review, 59, 654-77.

Ohtake, F. (2008). Inequality in Japan. Asian Economic Policy Review, 3, 87-109.

Scott, B.R. (2001). The Great Divide in the Global Village. Foreign Affairs, 80(1), 160-177.

Subir Lall, F. J. \& Papageorgiou, C. (2008). Rising Income Inequality: Technology, or Trade and Financial Globalization. IMF Working Paper.

Wood, A. (1994). North-South Trade, Employment, and Inequality. Oxford: Oxford University Press.

\section{Notes}

Note 1. To generate the impulse functions in Figure 4, we used the annual US data over the period of 1985 through 2007. The trade balance is adjusted to the ratio of trade balance and GDP. The VAR is estimated assuming a Wold ordering. Lags are chosen to be 1 using the Akaike criterion.

Note 2. VIF is a simple procedure in $\mathbf{R}$ (a programming language and software environment for statistical computing and graphics) to test the collinearity.

Note 3. The relative importance of each economic variable in Table 2-4 is defined as the unstandardized regression coefficient multiplied by the sample standard deviation of the corresponding independent variable X. It represents the change in dependent variable $\mathrm{Y}$ (i.e. the income inequality metric) associated with an increase of one standard deviation in $\mathrm{X}$, in original units of $\mathrm{Y}$. 
Table 1. The Cross-section Dimension of the Data

\begin{tabular}{|l|l|}
\hline Sector Dualism & $\begin{array}{l}\text { Agricultural dualism; manufacturing dualism; service dualism; GDP share of agriculture sector; GDP } \\
\text { share of manufacturing; GDP share of service. }\end{array}$ \\
\hline Labor Market Conditions & $\begin{array}{l}\text { Percentage of labor force across sectors (agriculture, service and manufacturing); percentage of female } \\
\text { labor force participation; percentage of households headed by females; unemployment rate; poverty rate. }\end{array}$ \\
\hline Monetary Stability & Annual inflation rate; federal funds rate. \\
\hline Demographic transition & Natural rate of population increase; seniority ratio. \\
\hline Overall education & College graduates ratio; secondary school enrollment ratio. \\
\hline Density of Unionization & Union density. \\
\hline Globalization & FDI / GDP; southern import penetration / GDP; net migration rate; trade balance / GDP; U.S. oil imports. \\
\hline
\end{tabular}

Table 2.Generalized Linear Regression Results: Gini Index

\begin{tabular}{|l|l|l|l|}
\hline Significant Variables & Estimates & STD & Relative Importance \\
\hline Dummy (time effect) & $-1.5831^{* * *}$ & 0.3232 & -0.5116 \\
\hline Seniority & $0.9378 \cdot$ & 0.6039 & 0.5663 \\
\hline Net migration rate & $0.5067^{*}$ & 0.2304 & 0.1167 \\
\hline Trade balance (a deficit) & $-0.9708^{* * *}$ & 0.1929 & -0.1873 \\
\hline Southern imports & $-1.6696^{* *}$ & 0.3167 & -0.5288 \\
\hline Agricultural dualism & $-0.6087 \cdot$ & 0.5362 & -0.3264 \\
\hline$\%$ Female in labor force & $0.3911^{*}$ & 0.1225 & 0.0479 \\
\hline Adjusted $\mathrm{R}^{2}$ & 0.9692 & \\
\hline
\end{tabular}

Note: $\cdot \mathrm{P}<0.1 ; * \mathrm{P}<0.05 ; * * \mathrm{P}<0.01$; *** $\mathrm{P}<0.001$ (two-sided test).

Table 3. Generalized Linear Regression Results: Atkinson Index

\begin{tabular}{|l|l|l|l|}
\hline Significant Variables & Estimates & STD & Relative Importance \\
\hline Dummy (time effect) & $-1.86390^{* * *}$ & 0.19439 & -0.3623 \\
\hline Net migration rate & $0.21285 *$ & 0.12580 & 0.0267 \\
\hline \% female-headed households & $-0.4552^{*}$ & 0.17536 & 0.0798 \\
\hline Service dualism & $0.24762^{* *}$ & 0.08066 & 0.0200 \\
\hline Union & $-0.46365^{*}$ & 0.19901 & 0.0923 \\
\hline Adjusted $\mathrm{R}^{2}$ & 0.9637 & \multicolumn{2}{|l|}{} \\
\hline \hline Secondary enrollment ratio & -0.05552 & 0.10016 & \\
\hline
\end{tabular}

Note: $\cdot \mathrm{P}<0.1 ; * \mathrm{P}<0.05 ; * * \mathrm{P}<0.01 ; * * * \mathrm{P}<0.001$ (two-sided test).

Table 4. Generalized Linear Regression Results: Theil Index

\begin{tabular}{|l|l|l|l|}
\hline Significant Variables & Estimates & STD & Relative Importance \\
\hline Dummy (time effect) & $-6.42753^{* * *}$ & 0.72790 & -4.6786 \\
\hline Trade balance (a deficit) & $-0.43751^{* * *}$ & 0.0823 & 0.0360 \\
\hline Net migration rate & $0.86385 \cdot$ & 0.44665 & 0.3858 \\
\hline \% Female in labor force & $0.49824 *$ & 0.19342 & 0.0964 \\
\hline Inflation & $0.37119 \cdot$ & 0.19076 & 0.0708 \\
\hline Adjusted $\mathrm{R}^{2}$ & 0.9827 & \multicolumn{2}{|l|}{} \\
\hline
\end{tabular}

Note: $\cdot \mathrm{P}<0.1 ; * \mathrm{P}<0.05 ; * * \mathrm{P}<0.01 ; * * * \mathrm{P}<0.001$ (two-sided test). 


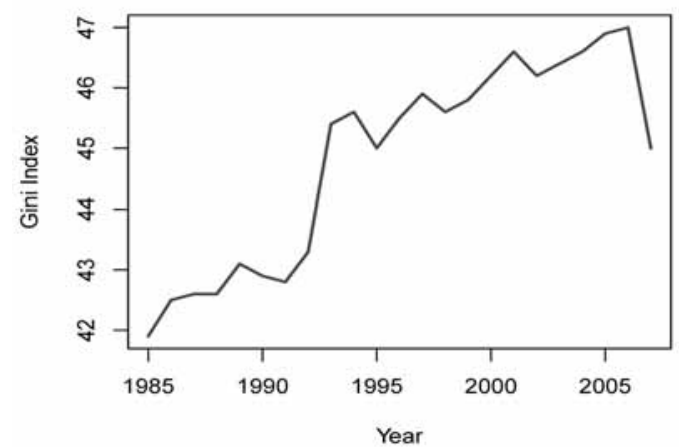

Figure 1. Income Inequality (Gini Coefficient) in the U.S. $1985-2007$

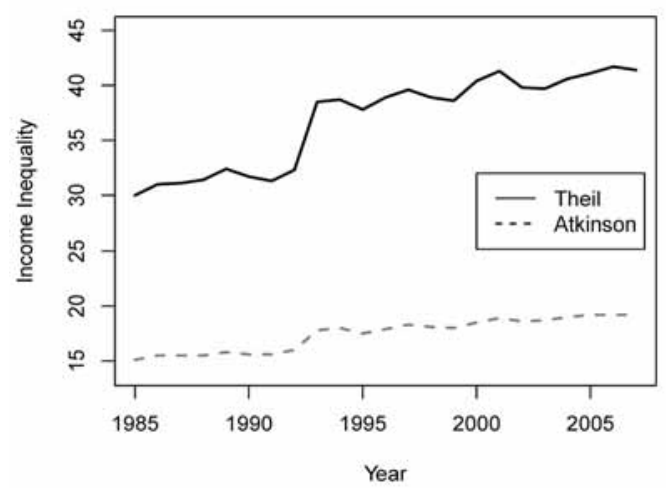

Figure 2. Income Inequality (Theil and Atkinson Coefficients) in the U.S. $1985-2007$

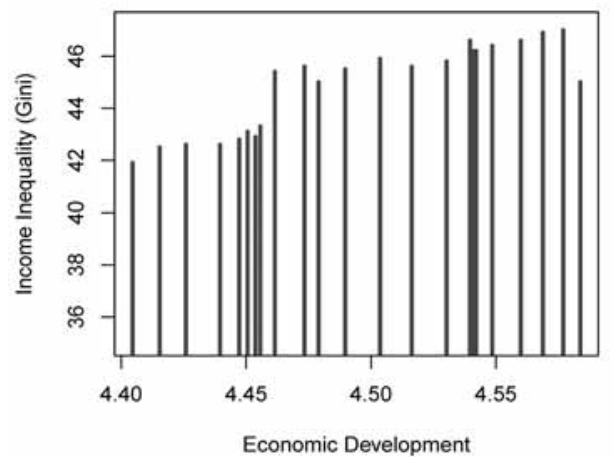

Figure 3. U.S. Income Inequality and Economic Development: 1985 - 2007 
Shock to Trade Balance

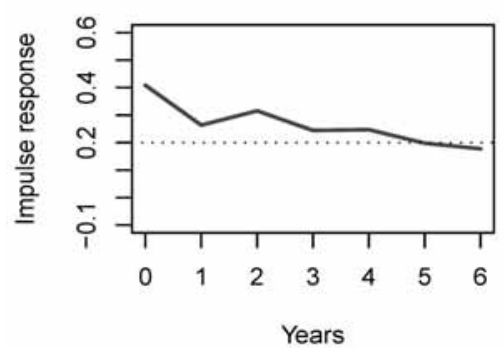

Response of Theil Index

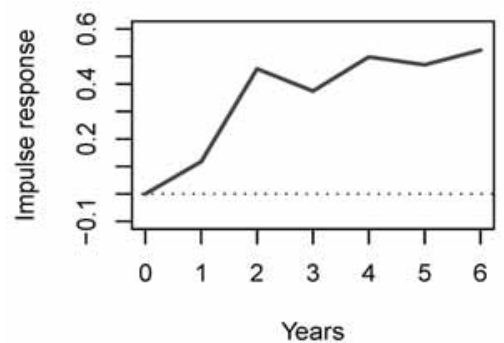

Response of Gini Index

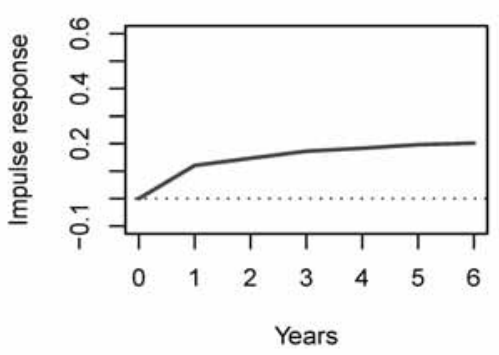

Response of Atkinson Index

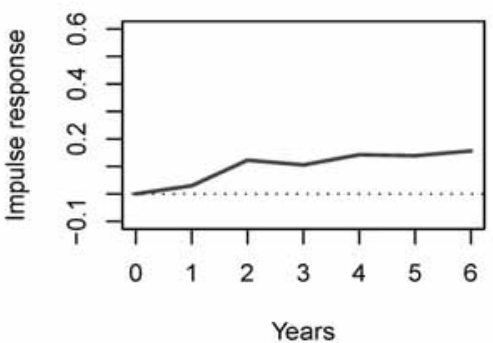

Figure 4. The Dynamic Responses of Inequality Indices from Structural VAR Estimation 